\title{
Article
}

\section{Optimization of Lignin Extraction from Pine Wood for Fast Pyrolysis by Using \#-valerolactone-Based Binary Solvent System}

Sureerat Jampa, Allen Puente-Urbina, Zhiqiang Ma, Sujitra

Wongkasemjit, Jeremy Scott Luterbacher, and Jeroen A. van Bokhoven

ACS Sustainable Chem. Eng., Just Accepted Manuscript • DOI: 10.1021/

acssuschemeng.8b05498 • Publication Date (Web): 20 Jan 2019

Downloaded from http://pubs.acs.org on January 30, 2019

\section{Just Accepted}

"Just Accepted" manuscripts have been peer-reviewed and accepted for publication. They are posted online prior to technical editing, formatting for publication and author proofing. The American Chemical Society provides "Just Accepted" as a service to the research community to expedite the dissemination of scientific material as soon as possible after acceptance. "Just Accepted" manuscripts appear in full in PDF format accompanied by an HTML abstract. "Just Accepted" manuscripts have been fully peer reviewed, but should not be considered the official version of record. They are citable by the Digital Object Identifier (DOI®). "Just Accepted" is an optional service offered to authors. Therefore, the "Just Accepted" Web site may not include all articles that will be published in the journal. After a manuscript is technically edited and formatted, it will be removed from the "Just Accepted" Web site and published as an ASAP article. Note that technical editing may introduce minor changes to the manuscript text and/or graphics which could affect content, and all legal disclaimers and ethical guidelines that apply to the journal pertain. ACS cannot be held responsible for errors or consequences arising from the use of information contained in these "Just Accepted" manuscripts. 


\title{
Optimization of Lignin Extraction from Pine Wood for Fast Pyrolysis by Using $\gamma$-valerolactone- Based Binary Solvent System
}

\author{
Sureerat Jampa a,b,\#, Allen Puente-Urbinaa,\#, Zhiqiang $\mathrm{Ma}^{\mathrm{a}}$, Sujitra Wongkasemjit ${ }^{\mathrm{b}}$, Jeremy S. \\ Luterbacherc, Jeroen A. van Bokhoven ${ }^{\mathrm{a}, \mathrm{d}, *}$
}

anstitute for Chemical and Bioengineering, Department of Chemistry and Applied Biosciences, ETH Zurich, HCI E 127, Vladimir-Prelog-Weg 1, 8093 Zurich, Switzerland

${ }^{\mathrm{b}}$ The Petroleum and Petrochemical College, Chulalongkorn University, Bangkok 10330, Thailand ${ }^{c}$ Laboratory of Sustainable and Catalytic Processing, Institute of Chemical Sciences and Engineering, École Polytechnique Fédérale de Lausanne (EPFL), 1015 Lausanne, Switzerland

${ }^{\mathrm{d}}$ Laboratory for Catalysis and Sustainable Chemistry, Paul Scherrer Institute, WLGA 135, 5232 Villigen, Switzerland

\footnotetext{
*Corresponding author: Tel.: +41 44632 5542. E-mail address: jeroen.vanbokhoven@chem.ethz.ch (Jeroen A. van Bokhoven)

\#These authors contributed equally to this work.
}

\begin{abstract}
Fast pyrolysis of lignin is a promising method to produce aromatic chemicals and fuels. Lignin structure and pyrolysis conditions determine the liquid yield and product selectivity. Extraction of pine wood using $\gamma$-valerolactone (GVL) mixed with water in the presence of diluted sulfuric acid obtains lignin (GVL-lignin) which shows different product yield and selectivity. The composition of the extraction medium influences the yield of GVL-lignin and affects its native structure. The GVLto-water ratio affects the lignin yield without significantly modifying the structure of the extracted lignin, whereas the sulfuric acid concentration affects both the extraction yield and the extracted
\end{abstract}


lignin structure. These structural changes influence the products distribution after fast pyrolysis, which generates phenols and alkoxy phenols as the main products in the liquid fraction. Lignin extracted with a mixture of $4 / 1$ of $\mathrm{GVL} / \mathrm{H}_{2} \mathrm{O}(\mathrm{w} / \mathrm{w})$ with $0.075 \mathrm{M}$ sulfuric acid solution produces the highest pyrolysis liquid yield. Pyrolysis of GVL-lignin at $750{ }^{\circ} \mathrm{C}$ generates the maximum liquid yield. The amount of phenols in fast pyrolysis products increases with increasing temperature and sulfuric acid concentration used in the GVL-lignin extraction. This indicates that the extraction conditions of GVL-lignin may be optimized to increase the selectivity in fast pyrolysis.

Keywords: lignocellulosic biomass, lignin, $\gamma$-valerolactone (GVL), fast pyrolysis, bio-oil

\section{Introduction}

Owing to the increase in worldwide population in recent years, fossil resources consumption has also increased, leading to concerns about their depletion and negative effects on the environment. Therefore, processes facilitating the use of alternative sustainable feedstocks receive more and more consideration. Among the alternative resources, biomass is a promising raw material for producing value-added chemicals, fuels and energy with a low carbon footprint. ${ }^{1-3}$

Lignocellulosic biomass is an exceptional renewable feedstock to obtain useful products (e.g. chemicals and fuels) and energy through biochemical or thermochemical transformations. ${ }^{4}$ The relevance of a certain type of biomass in a specific region depends on its availability, which often depends on technical, economic, environmental and other factors. ${ }^{5}$ In Switzerland, there is a substantial sustainable potential for forest energy wood, wood from landscape maintenance and waste wood, with softwoods being the majority of domestic wood species produced. ${ }^{5,6}$ In general, lignocellulosic biomass is mainly composed of cellulose, hemicellulose and lignin, but also has small amounts of ash and extractives. ${ }^{7}$ Each type of lignocellulosic biomass contains different amounts of these components. In all cases, lignin is an important fraction that has a high potential to be used as a renewable source for producing fuels and aromatic compounds. ${ }^{8}$

Lignin has a complex three-dimensional amorphous structure. It has been described conventionally as a polymer of phenylpropane units (monolignols), namely $p$-coumaryl, coniferyl and 
sinapyl alcohols, also called units H, G and S.9,10 Each unit in the lignin structure is connected by various ether and carbon-carbon linkages, such as $\beta-\mathrm{O}-4,4-\mathrm{O}-5, \alpha-\mathrm{O}-4, \beta-\beta, \beta-5, \beta-1$ and $5-5 .{ }^{11,12}$ Generally, softwood lignin contains coniferyl alcohol and hardwood lignin both coniferyl and sinapyl alcohols as predominant units. ${ }^{13}$ However, lignin properties and its isolation yield depend on its source (e.g. softwood or hardwood) and the extraction technique applied. These factors also influence the products that can be obtained from further processing of such lignin. Thus, it is necessary to use a suitable extraction method to obtain high yields as well as adequate characteristics for the intended use.

The organosolv extraction is one of the most popular processes to isolate cellulose, hemicellulose and lignin from lignocellulosic biomass. This method can solubilize lignin and separate it from the lignocellulosic feedstocks, usually along with hemicellulose, by using a mixture of organic solvents and inorganic acids catalysts such as hydrochloric acid and sulfuric acid. ${ }^{14}$ Regular solvents used in this process include methanol, ethanol, acetone, ethylene glycol, triethylene glycol and tetrahydrofurfuryl alcohol. ${ }^{15}$ Due to the milder conditions required and the solubilization of the lignin, the lignin's structure can generally be better preserved than using other extraction methods such as Kraft or aqueous methods though some condensation does occur. ${ }^{16-18}$ Thus, the organosolv method generates lignin which is more amenable towards depolymerization. ${ }^{19}$ However, this method still has some drawbacks, such as the need for solvent recovery, high-pressure operation conditions, associated risks due to high volatility and flammability of the organic solvents used as well as their toxicity to the environment and human health, among others, which contribute to a low economic competitiveness with respect to other fractionation methods. ${ }^{20-22}$ In addition, side reactions such as cleavage of aryl ether linkages, ethoxylation and condensation reactions can take place, resulting in undesired structure modifications..$^{22,23}$

Trying to minimize these problems, green solvents have attracted attention in recent years for biomass processing. ${ }^{24}$ Among them, $\gamma$-valerolactone (GVL) is a promising solvent for biomass fractionation with the possibility of obtaining the extracted lignin by addition of water. ${ }^{25-31}$ It has favorable physical and chemical properties for various applications such as low melting point (-31 ${ }^{\circ} \mathrm{C}$ ), high boiling point $\left(207^{\circ} \mathrm{C}\right.$ ) and low volatility (vapor pressure of 0.44 mbar at $25^{\circ} \mathrm{C}$ ), 
renewability, high open cup flash point $\left(96^{\circ} \mathrm{C}\right)$, non-toxicity, stability, biodegradability and also the possibility to be mixed or chemically modified to tailor other specific purposes..$^{32-34}$

Lignin can be converted into useful liquids (bio-oil), gases and char by pyrolysis as thermochemical decomposition process. ${ }^{4}$ It can be classified as fast pyrolysis or slow pyrolysis depending on its operation conditions. ${ }^{35}$ Interestingly, fast pyrolysis generates a higher amount of biooil, an alternative source of solvents, fuels and other high value chemicals. ${ }^{36-38}$ In fast pyrolysis, lignin is thermally treated using very high heating rates and short vapor residence times, followed by a rapid cooling of the pyrolysis vapors to obtain bio-oil containing important amounts of aromatic compounds. ${ }^{39,40}$ In addition, fast pyrolysis can be developed under catalytic and non-catalytic conditions, which together with the process conditions, determine the products distribution. ${ }^{41-45}$ In this study, pine wood (softwood) was employed as the lignocellulosic biomass source for lignin extraction with $\mathrm{GVL} / \mathrm{H}_{2} \mathrm{O}$ solvent in the presence of sulfuric acid. The influence of extraction conditions (i.e. time, temperature, sulfuric acid concentration and $\mathrm{GVL} / \mathrm{H}_{2} \mathrm{O}$ ratio) on the process and lignin structure was analyzed. Then, the extracted lignin underwent fast pyrolysis at various temperatures and the corresponding products were determined. The objective of this work was to find the best conditions for lignin extraction from pine wood by using $\mathrm{GVL} / \mathrm{H}_{2} \mathrm{O}$ solvent to maximize the organic liquid yield obtained by fast pyrolysis.

\section{Experimental Section}

\section{Chemicals}

All chemicals were obtained as reagent grade and used without further purification. The commercial lignin that was used was softwood alkaline lignin supplied by Tokyo Chemical Industry UK Ltd. (product number: L0082).

\section{Lignin extraction}

Pine wood was dried at $100^{\circ} \mathrm{C}$ and then milled to particles of $<180 \mu \mathrm{m}$ by steel ball milling. The milled pine wood was suspended in $\mathrm{GVL} / \mathrm{H}_{2} \mathrm{O}$ containing sulfuric acid, using a solid-to-solvent ratio of $1 / 10 \mathrm{w} / \mathrm{w}$. The resulting mixture was heated in a $100 \mathrm{ml}$ teflon reactor with constant stirring, varying temperature $\left(120,140\right.$ and $\left.160^{\circ} \mathrm{C}\right)$, time $(1,3,5,15,21,24$ and $27 \mathrm{~h})$, sulfuric acid 
concentration (by addition of $0.025,0.050,0.075,0.125,0.175,0.225$ and $0.275 \mathrm{M}$ sulfuric acid aqueous solutions, $10 \mathrm{wt} \%$ with respect to $\mathrm{GVL} / \mathrm{H}_{2} \mathrm{O}$ solvent) and initial $\mathrm{GVL} / \mathrm{H}_{2} \mathrm{O}$ ratio $(4 / 1,2 / 1$ and 1/1 w/w). Table S1 has additional details about the solutions used for lignin extraction. Then, the products were separated by filtration. The lignin contained in the filtrate was precipitated using water and the sludge stirred for $30 \mathrm{~min}$. The resulting solid (i.e. lignin, Table S2) was filtered, washed with water and dried overnight at $100^{\circ} \mathrm{C}$.

\section{Lignin characterization}

Fourier-transform infrared spectroscopy (FTIR) measurements were developed using a BioRad Excalibur Series FTS 3000 spectrometer. The samples were pelletized with $\mathrm{KBr}$, using a proportion of $1 \mathrm{mg}$ of lignin per $40 \mathrm{mg}$ of $\mathrm{KBr}$. Each spectrum was obtained by averaging 256 scans in a wavenumber range of $800-4000 \mathrm{~cm}^{-1}$ with a resolution of $2 \mathrm{~cm}^{-1}$.

Nuclear magnetic resonance (NMR) spectra were recorded in a Bruker $500 \mathrm{MHz}$ Ultrashield spectrometer at room temperature. Samples were prepared dissolving $30 \mathrm{mg}$ of lignin in $0.9 \mathrm{~mL}$ of DMSO- $\mathrm{d}_{6} .{ }^{1} \mathrm{H}$ NMR experiments were performed using the pulse sequence zg30, 16 scans, 2 dummy scans, $1 \mathrm{~s}$ of relaxation delay and $3.27 \mathrm{~s}$ of acquisition time. The heteronuclear single quantum correlation (HSQC) spectra were obtained using the pulse program hsqcetgpsisp2.2, 8 scans, 4 dummy scans, $0.5 \mathrm{~s}$ of relaxation delay, spectral widths of $6010 \mathrm{~Hz}$ (12 to $0 \mathrm{ppm}$ ) for ${ }^{1} \mathrm{H}$ dimension (F2) and $27669 \mathrm{~Hz}$ (220 to $0 \mathrm{ppm}$ ) for ${ }^{13} \mathrm{C}$ dimension (F1), 2048 points recorded for ${ }^{1} \mathrm{H}$ dimension and 1024 points for ${ }^{13} \mathrm{C}$ dimension, and acquisition times of $0.17 \mathrm{~s}$ for ${ }^{1} \mathrm{H}$ dimension and $0.018 \mathrm{~s}$ for ${ }^{13} \mathrm{C}$ dimension. The results were analyzed using TopSpin 3.5 software.

Thermogravimetric analyses (TGA) were performed in a Mettler Toledo TGA/SDTA851 ${ }^{\mathrm{e}}$ thermogravimetric analyzer. Lignin samples were heated from $30{ }^{\circ} \mathrm{C}$ to $760^{\circ} \mathrm{C}$ with a heating rate of $10{ }^{\circ} \mathrm{C} \mathrm{m^{-1 }}$ under nitrogen flow $\left(50 \mathrm{~cm}^{3} \mathrm{~min}^{-1}\right)$.

\section{Fast pyrolysis and products analyses}

Fast pyrolysis experiments were carried out in a CDS Analytical 5150 pyrolyzer using an open quartz tube resistively heated by a platinum coil. Lignin samples of $1.5-2 \mathrm{mg}$ were immobilized in the middle of the reactor by quartz wool and pyrolyzed at a heating rate of $20^{\circ} \mathrm{C} / \mathrm{ms}$, a residence time of $20 \mathrm{~s}$ and varying the pyrolysis temperature from 550 to $850{ }^{\circ} \mathrm{C}$. 
Pyrolysis products were directly transferred at $300{ }^{\circ} \mathrm{C}$ into an Agilent $7890 \mathrm{~A}$ gas chromatograph using helium at $1.1 \mathrm{~mL} \mathrm{~min}^{-1}$ as carrier gas, equipped with a thermal conductivity detector (TCD) and an Agilent 5975C mass selective detector (MSD). The oven was programmed to start at $40{ }^{\circ} \mathrm{C}$, hold for $5 \mathrm{~min}$ and then heat up to $260{ }^{\circ} \mathrm{C}$ at $10{ }^{\circ} \mathrm{C} \mathrm{min}^{-1}$, temperature that was held for $25 \mathrm{~min}$. An injector temperature of $300^{\circ} \mathrm{C}$ and a split ratio of $35: 1$ were used. The flow was split to analyze condensable pyrolysis products in one stream and gases in another. Condensable pyrolysis products were separated with a HP-5MS column $(30 \mathrm{~m} \times 0.25 \mathrm{~mm} \times 0.25 \mu \mathrm{m})$ and analyzed by means of the mass spectrometry detector, where peaks were identified using the NIST08 mass spectrum library and the corresponding compounds classified according to their functional groups into seven categories: thiols; non-aromatic esters, ketones, aldehydes, furans and acids; aromatic hydrocarbons; alkoxy aromatic hydrocarbons; phenols; alkoxy phenols and non-identified (typical quantifications with less than $\pm 5 \%$ error). Non-condensable gases were separated with Agilent Plot/Q and molecular sieve capillary columns (both $30 \mathrm{~m}$ x $0.53 \mathrm{~mm}$ ) and quantified using the TCD, which was calibrated for the most predominant gaseous molecules $\left(\mathrm{CO}, \mathrm{CO}_{2}, \mathrm{CH}_{4}, \mathrm{C}_{2} \mathrm{H}_{4}, \mathrm{C}_{2} \mathrm{H}_{6}, \mathrm{C}_{3} \mathrm{H}_{6}\right.$ and $\left.\mathrm{C}_{3} \mathrm{H}_{8}\right)$. In addition, the remaining solid after pyrolysis was measured gravimetrically and the liquid fraction was calculated by mass difference. All the measurements were performed at least in duplicate and reported with $95 \%$ confidence level.

\section{Results and discussion}

Effect of pyrolysis temperature on pyrolysis yields and liquid product distribution of GVL-lignin

The pyrolysis temperature is an important operational factor for this type of process. Different temperatures (i.e. $550,650,750$ and $850{ }^{\circ} \mathrm{C}$ ) were used to evaluate the fast pyrolysis of GVL-lignin from pine wood using a heating rate of $20^{\circ} \mathrm{C} / \mathrm{ms}$ and residence time of $20 \mathrm{~s}$. The pyrolysis products can be divided into three phases, namely liquid (bio-oil), solid (char) and gas. ${ }^{41-48}$ Figure 1A illustrates the yields of liquid, char and gaseous products as a function of the pyrolysis temperature of GVL-lignin obtained using a mixture of $4 / 1 \mathrm{GVL} / \mathrm{H}_{2} \mathrm{O}(\mathrm{w} / \mathrm{w})$ and $0.075 \mathrm{M}$ sulfuric acid at $160{ }^{\circ} \mathrm{C}$ for $24 \mathrm{~h}$. The liquid fraction increased from 550 to $(650-850){ }^{\circ} \mathrm{C}$, because of an increase in primary decomposition of 
lignin at higher temperatures..$^{49,50}$ In contrast, the char yield decreased from 550 to $(650-850){ }^{\circ} \mathrm{C}$. This reduction originated either from a greater primary decomposition of lignin or from secondary decomposition of the char residue at higher temperatures. ${ }^{51}$ Gas yield increased steadily with temperature from $4.6 \%$ to $12.6 \%$. The higher gas yields generated at higher temperature came from the secondary cracking of the pyrolysis vapor and secondary decomposition of the char to non-condensable gaseous products. ${ }^{52-54}$ These trends obtained confirm that the pyrolysis temperature plays a dominating role in determining product distribution.

Figure 1B presents the liquid product distribution of GVL-lignin using varying pyrolysis temperature (water not included). The compounds are classified into seven groups: thiols; non-aromatic esters, ketones, aldehydes, furans and acids; aromatic hydrocarbons; alkoxy aromatic hydrocarbons; phenols; alkoxy phenols and non-identified. The amount of phenol alkoxy compounds produced decreased with increasing pyrolysis temperature. On the contrary, phenol products increased with increasing pyrolysis temperature. Horne and Williams ${ }^{51}$ reported that compounds in the group of alkoxy phenols (methoxyphenol, dimethoxyphenol and their derivatives) form at low temperatures. In addition, using higher temperature increases the extent of secondary reactions in which such large phenolic compounds thermally breakdown to phenol or they undergo alkylation, increasing the quantity of alkylated phenols..$^{51}$
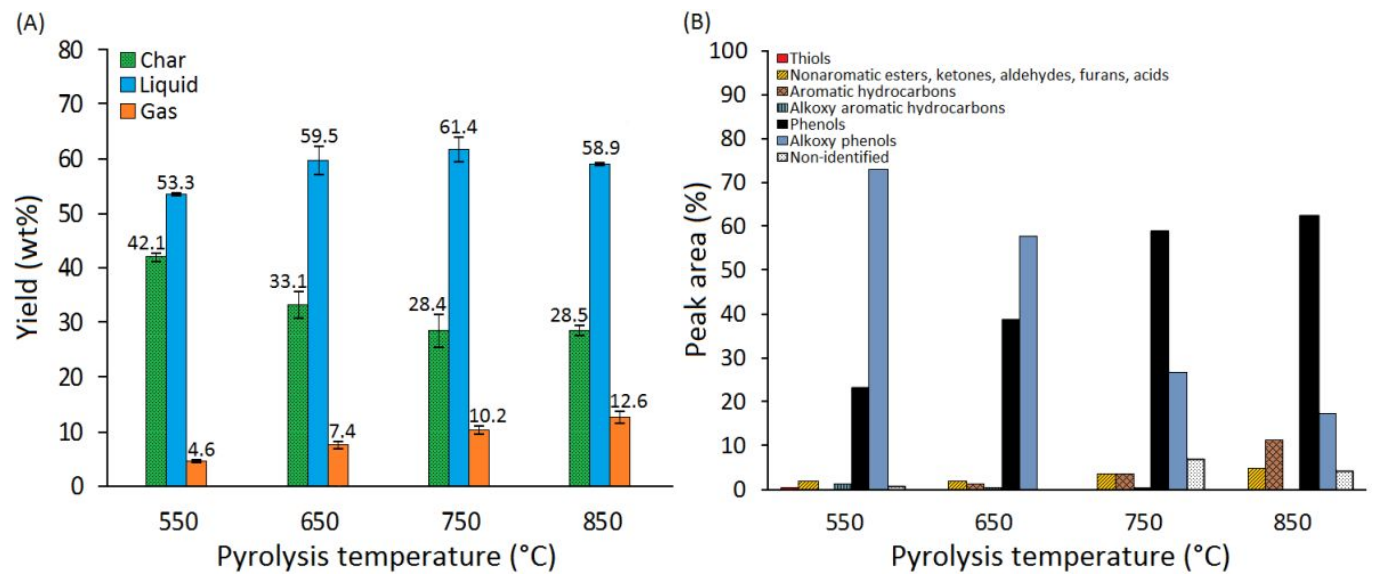

Figure 1 Effect of temperature on pyrolysis of extracted lignin with a mixture of $4 / 1 \mathrm{GVL} / \mathrm{H}_{2} \mathrm{O}(\mathrm{w} / \mathrm{w})$ and $0.075 \mathrm{M}$ sulfuric acid at $160{ }^{\circ} \mathrm{C}$ for $24 \mathrm{~h}$. (A) Yields of char, liquid and gas and (B) Liquid product distribution. 


\section{Effect of GVL/ $\mathrm{H}_{2} \mathrm{O}$ ratio on GVL-lignin and pyrolysis yield and liquid product distribution}

Extracted lignin yields of 19.7, 18.6 and $15.0 \mathrm{wt} \%$ were obtained using mixtures of 4/1, 2/1 and $1 / 1$ of $\mathrm{GVL} / \mathrm{H}_{2} \mathrm{O}(\mathrm{w} / \mathrm{w})$ with $0.075 \mathrm{M}$ sulfuric acid solution at $160{ }^{\circ} \mathrm{C}$ for $24 \mathrm{~h}$ (Tables S1 and S2). During lignin extraction processes, lignin was first released from the complete lignocellulosic material by hydrolytic cleavage of the ether bond in the lignin-carbohydrate complex or between lignin moieties, and then dissolved. ${ }^{55}$ These cleavages are promoted by the presence of acid, either generated in the process, such as acetic acid generated by cleavage of acetyl groups in hemicellulose ${ }^{56}$, or added externally as in our case.

Lignin extraction with $\mathrm{GVL} / \mathrm{H}_{2} \mathrm{O}$ is a complex process. Lignin solubility in $\mathrm{GVL} / \mathrm{H}_{2} \mathrm{O}$ is insignificant up to $32 \mathrm{wt} \%$ of GVL. ${ }^{55}$ Above this concentration, the mixture tends to split into two phases and lignin solubility greatly increases. ${ }^{55}$ In addition, it depends on the temperature of the medium as well as the presence of acids, which can promote lignin dissolution ${ }^{55-57}$ and also the establishment of an equilibrium of GVL with its ring opening product 4-hydroxyvaleric acid, which in our study remained at low concentration because of the low concentration of sulfuric acid. ${ }^{58}$ The lowest content of GVL in the solvent mixture was ca. $45 \mathrm{wt} \%$ for the combination of $1 / 1$ of $\mathrm{GVL} / \mathrm{H}_{2} \mathrm{O}(\mathrm{w} / \mathrm{w})$ with the different sulfuric acid solutions, and above $50 \mathrm{wt} \%$ for the other mixtures (Table S1). For GVL contents above $50 \mathrm{wt} \%$, Xue et al..$^{59}$ explained that the GVL-based binary solvent system can promote the solubility of lignin due to effects such as the breakdown of the strong hydrogen bonds in the lignin structure. Similar results were reported by Fang and co-workers, which found the greatest delignification of birch (a hardwood) sawdust at a GVL concentration between 50 and $65 \mathrm{wt} \% .{ }^{26}$ In mixtures with GVL contents below $50 \mathrm{wt} \%$, water acts as an antisolvent for lignin extraction, because a larger amount of water strongly interacts with GVL molecules, resulting in fewer interactions with lignin, decreasing its solubility. ${ }^{59}$ However, the complexity of the process is advantageous for product handling, considering that lignin is easily precipitated by water addition. Furthermore, a liquid phase split can be used as an effective chemical recovery pathway. ${ }^{60}$

The lignins extracted from pine wood by varying the $\mathrm{GVL} / \mathrm{H}_{2} \mathrm{O}(\mathrm{w} / \mathrm{w})$ ratio were pyrolyzed at $750{ }^{\circ} \mathrm{C}$ with a heating rate of $20^{\circ} \mathrm{C} / \mathrm{ms}$ and a residence time of $20 \mathrm{~s}$ (Figure $2 \mathrm{~A}$ ). Initial $\mathrm{GVL} / \mathrm{H}_{2} \mathrm{O}$ ratios of $4 / 1$ and 2/1 (w/w) presented no significant differences on the liquid yield. However, the use of initial 
$1 / 1 \mathrm{GVL} / \mathrm{H}_{2} \mathrm{O}(\mathrm{w} / \mathrm{w})$ gave a much lower liquid yield. Considering that initial $\mathrm{GVL} / \mathrm{H}_{2} \mathrm{O}$ ratio of $4 / 1$ (w/w) provides high lignin extraction yield (Table S2) while affords high liquid yield in pyrolysis (Figure 2A), this initial ratio seems to be the optimal among those used.

Table 1 compares the liquid yields of the pyrolysis of different lignins under distinct conditions. The liquid yield of GVL-lignin was higher than that of commercial lignin. GVL-lignin pyrolysis results were compared to others previously reported by Custodis et al. ${ }^{44}$, which studied similar fast pyrolysis of lignins separated by dioxane-, Klason-, and organsolv-methods. Both softwood and hardwood lignins extracted by the organosolv method (using $60 \mathrm{vol} \%$ ethanol with $5 \mathrm{wt} \%$ sulfuric acid) ${ }^{44}$ produced lower liquid yields than those obtained from lignin extracted by $\mathrm{GVL} / \mathrm{H}_{2} \mathrm{O}$. Furthermore, the liquid yield of GVL-lignin was compared to that of dioxane softwood and hardwood lignin as well as Klason softwood and hardwood lignins. The liquid yield followed the order of Klason hardwood lignin $(68 \mathrm{wt} \%)>$ dioxane softwood lignin $(66 \mathrm{wt} \%)>$ dioxane hardwood lignin $(65 \mathrm{wt} \%)>$ GVL softwood lignin $(61$ $w t \%)>$ Klason softwood lignin $(56 \mathrm{wt} \%)>$ organolsolv softwood lignin $(55 \mathrm{wt} \%)>$ organolsolv hardwood lignin $(53 \mathrm{wt} \%)>$ commercial lignin $(40 \mathrm{wt} \%)$. For other fast pyrolysis results shown in Table 1, the liquid yield is affected both by the type of lignin and by the conditions of the process. ${ }^{61-66}$

Figure 2B illustrates the pyrolysis liquid product distribution of GVL-lignin extracted with various $\mathrm{GVL} / \mathrm{H}_{2} \mathrm{O}$ ratios. The two major classes of compounds in the liquid fractions were phenols and alkoxy phenols. All conditions showed similar amounts of phenols and alkoxy phenols in the corresponding pyrolysis liquid fraction of about $60 \%$ and $25 \%$, respectively. There was no significant difference in the content of phenols and alkoxy phenols compounds in the pyrolysis liquid product of lignin, because the structures of GVL-lignin extracted by using different initial $\mathrm{GVL} / \mathrm{H}_{2} \mathrm{O}$ ratios of 4/1, 2/1 and 1/1 (w/w) were very similar, as confirmed by 2D HSQC NMR.

Figure 3 shows the 2D HSQC NMR spectra of GVL-lignin (detailed assignments and one ${ }^{1} \mathrm{H}$ NMR spectrum are presented in Table S3, Table S4 and Figure S1). These were classified into two main cross-signal regions, consisting of a side-chain $\left(\delta_{\mathrm{H}} / \delta_{\mathrm{C}} 2.5-5.8 / 50-90 \mathrm{ppm}\right)$ region and an aromatic/unsaturated $\left(\delta_{\mathrm{H}} / \delta_{\mathrm{C}} 6.0-8.0 / 100-160 \mathrm{ppm}\right)$ region. ${ }^{67-69}$. Furthermore, Figure 4 exhibits the main classical substructures of GVL-lignin. In the side-chain region of all GVL-lignins, the C-H correlation in methoxy groups showed a strong cross-signal at $\delta_{\mathrm{H}} / \delta_{\mathrm{C}} 3.73 / 55.6 \mathrm{ppm}$. The two main substructures 
observed in the HSQC spectra were $\mathrm{A}_{\gamma}$ and $\mathrm{C}_{\gamma}$. The $\mathrm{C}_{\gamma}-\mathrm{H}_{\gamma}$ correlation in the $\beta-\mathrm{O}-4$ ' substructures (A) was clearly found in the $\delta_{\mathrm{H}} / \delta_{\mathrm{C}}$ range of $3.21-3.72 / 60.0-60.7 \mathrm{ppm}$. The cross-signal at $\delta_{\mathrm{H}} / \delta_{\mathrm{C}} 3.66 / 63.3$ ppm corresponded to the $\mathrm{C}_{\gamma}-\mathrm{H}_{\gamma}$ correlation in $\beta-5^{\prime}$ (phenylcoumaran) substructures (C). The major cross-signals appearing in the aromatic/unsaturated region of the HSQC spectra corresponded to guaiacyl (G) units, as expected for a softwood. ${ }^{13}$ There were three main C-H correlations in guaiacyl (G) units, causing three different cross-signals. The $\mathrm{C}_{5}-\mathrm{H}_{5}, \mathrm{C}_{6}-\mathrm{H}_{6}$ and $\mathrm{C}_{2}-\mathrm{H}_{2}$ correlations in guaiacyl units $\left(\mathrm{G}_{5}, \mathrm{G}_{6}\right.$ and $\left.\mathrm{G}_{2}\right)$ were observed at $\delta_{\mathrm{H}} / \delta_{\mathrm{C}}$ of $6.71 / 115.0,6.83 / 119.5$ and $6.98 / 115.5$, respectively. In both side-chain and aromatic/unsaturated regions, the HSQC spectra of all GVL-lignins extracted with various $\mathrm{GVL} / \mathrm{H}_{2} \mathrm{O}$ ratios presented the same cross-signal patterns, indicating that the $\mathrm{GVL} / \mathrm{H}_{2} \mathrm{O}$ ratio for lignin extraction does not have a significant effect on the structure of GVL-lignin.
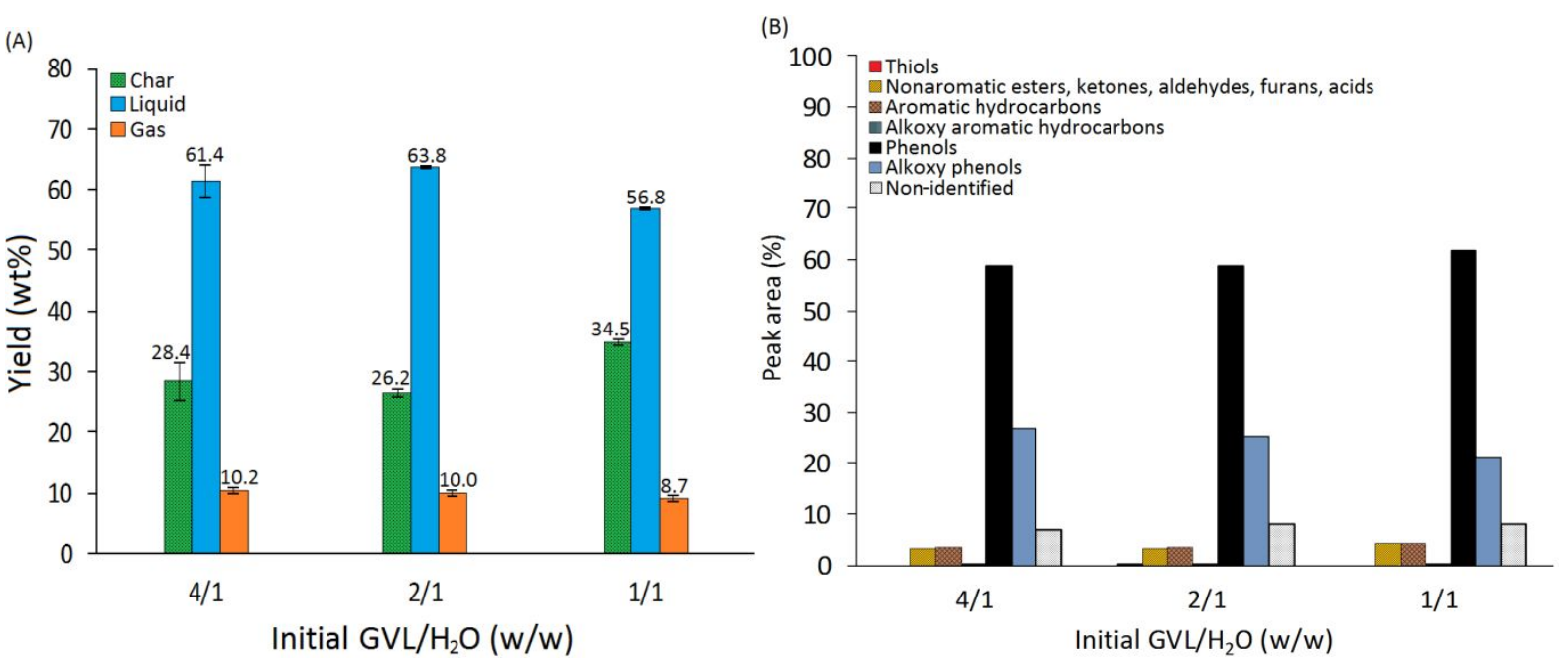

Figure 2 Effect of extracted lignin with various initial $\mathrm{GVL} / \mathrm{H}_{2} \mathrm{O}$ ratios (with $0.075 \mathrm{M}$ sulfuric acid at $160{ }^{\circ} \mathrm{C}$ for $24 \mathrm{~h}$ ) on pyrolysis. (A) Yields of char, liquid and gas and (B) Liquid product distribution. 
Table 1 Liquid yields comparison of each lignin after fast pyrolysis.

\begin{tabular}{|c|c|c|c|}
\hline Type of lignin & $\begin{array}{l}\text { Pyrolysis } \\
\text { temperature } \\
\left({ }^{\circ} \mathrm{C}\right)\end{array}$ & Liquid yield (wt\%) & References \\
\hline GVL lignin from pine wood & 750 & 61 & \multirow{2}{*}{ This study } \\
\hline Commercial lignin & 750 & 40 & \\
\hline Dioxane softwood lignin & 750 & 66 & \multirow{6}{*}{$\begin{array}{l}\text { Custodis et } \\
\qquad a .^{44}\end{array}$} \\
\hline Klason softwood lignin & 750 & 56 & \\
\hline Organosolv softwood lignin & 750 & 55 & \\
\hline Dioxane hardwood lignin & 750 & 65 & \\
\hline Klason hardwood lignin & 750 & 68 & \\
\hline Organosolv hardwood lignin & 750 & 53 & \\
\hline Kraft lignin & 650 & 37.4 & Ma et al. ${ }^{42}$ \\
\hline Alkali lignin & 650 & 39.5 & $\begin{array}{l}\text { Ma et al. }{ }^{45} \\
\text { Ma et al. }{ }^{47} \\
\text { Ma et al. }{ }^{48}\end{array}$ \\
\hline Alcell lignin & 600 & 17.2 & \multirow{2}{*}{ Jiang et al. ${ }^{61}$} \\
\hline Asian lignin & 600 & 15.5 & \\
\hline Lignin (byproduct of fermenting) & $500-550$ & 34 & $\begin{array}{c}\text { Trinh et } \\
\text { al. }{ }^{62}\end{array}$ \\
\hline $\begin{array}{l}\text { Pyrolytic lignin precipitated from } \\
\text { water }\end{array}$ & 600 & 40 & \multirow{4}{*}{ Zhao et al. ${ }^{63}$} \\
\hline $\begin{array}{l}\text { Pyrolytic lignin separated } \\
\text { from the mixture of glycerol and } \\
\text { bio-oil }\end{array}$ & 600 & 37 & \\
\hline Alkali lignin & 600 & 6 & \\
\hline Kraft lignin & 600 & 7 & \\
\hline Alkali lignin A & 650 & ca. 21.5 & \multirow{2}{*}{ Li et al. ${ }^{64}$} \\
\hline Alkali lignin B & 650 & ca. 46.7 & \\
\hline Organosolv lignin & 600 & ca. 22.0 & $\begin{array}{l}\text { Patwardhan } \\
\text { et al. }{ }^{65} \\
\text { Fan et al. }{ }^{66}\end{array}$ \\
\hline
\end{tabular}



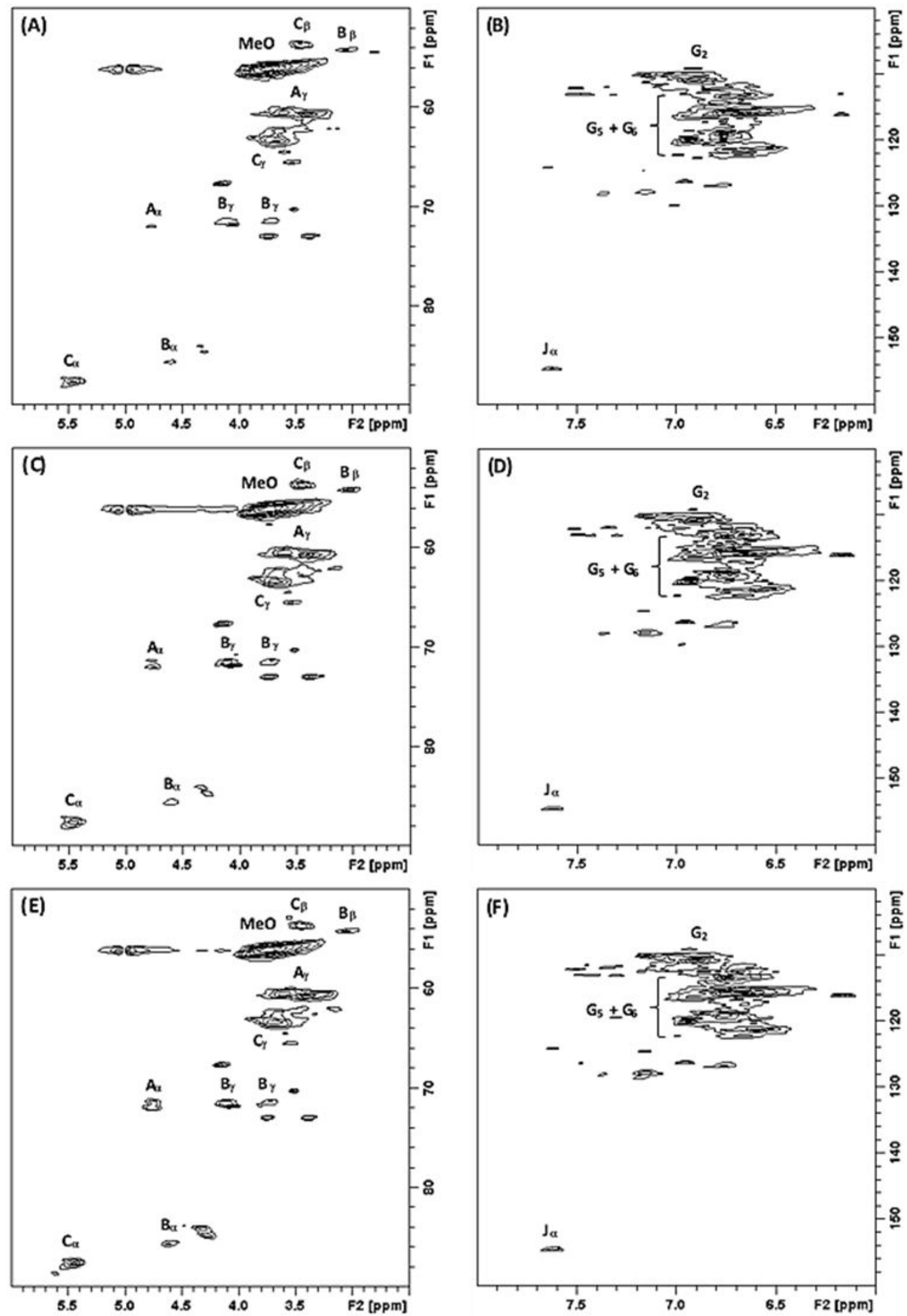

Figure 3 Side-chain $\left(\delta_{\mathrm{H}} / \delta_{\mathrm{C}} 2.5-5.8 / 50-90\right)$ and aromatic/unsaturated $\left(\delta_{\mathrm{H}} / \delta_{\mathrm{C}} 6.0-8.0 / 100-160\right)$ regions in the 2D HSQC NMR spectra of extracted lignin with mixtures of various initial GVL/ $\mathrm{H}_{2} \mathrm{O}$ ratios and $0.075 \mathrm{M}$ sulfuric acid at $160{ }^{\circ} \mathrm{C}$ for $24 \mathrm{~h}$. (A, B) initial GVL/ $\mathrm{H}_{2} \mathrm{O}$ of $4 / 1$ (w/w); (C, D) initial GVL/ $\mathrm{H}_{2} \mathrm{O}$ of $2 / 1(w / w)$ and $(E, F)$ initial $\mathrm{GVL} / \mathrm{H}_{2} \mathrm{O}$ of $1 / 1(\mathrm{w} / \mathrm{w})$. 
<smiles>CCOc1ccc(C(O)C(CO)Oc2ccc(C)cc2OC)cc1OC</smiles>

A<smiles>CCOc1ccc(C2Oc3c(OC)cc(CC)cc3C2C(O)O)cc1OC</smiles>

C<smiles>CCOc1ccc(C2O[I]C3C(c4ccc(OCC)c(OC)c4)OCC23)cc1OC</smiles>

B<smiles>CCOc1ccc(C=CC=O)cc1OC</smiles>

Figure 4 Main classical substructures, involving different side-chain linkages and aromatic units, identified by 2D HSQC NMR in extracted lignin from pine wood: (A) $\beta-O-4$ ' substructure; (B) resinol substructure, formed by $\beta-\beta^{\prime}$ coupling and $\alpha-\mathrm{O}-\gamma^{\prime}$ and $\gamma-\mathrm{O}-\alpha^{\prime}$ bonding during quinone methide rearomatization; (C) phenylcoumaran, formed by $\beta-5$ ' coupling and subsequent $\alpha-\mathrm{O}-4$ ' bonding; (G) guaiacyl unit; (J) cinnamaldehyde end-groups. 
Effect of sulfuric acid concentration on GVL-lignin and pyrolysis yield and liquid product distribution

Figure 5A shows the extracted lignin yields with various sulfuric acid concentrations. In the concentration range provided by the addition of $0.025-0.175 \mathrm{M}$ sulfuric acid solutions (see Table S1 for detailed information about specific concentrations), the extracted lignin yield increased with increasing concentration. The extracted lignin yields remained almost constant for higher concentrations. The concentration of sulfuric acid also influenced pyrolysis yield and liquid product distribution of GVLlignin (Figure 5A and 5B). The increase of sulfuric acid concentration provided by the addition of solutions from 0.075 to $0.175 \mathrm{M}$ caused obvious changes in liquid and char yields. The liquid yield decreased and the char yield increased with increasing sulfuric acid concentration in this range, while stable behaviors appeared outside of it. Thus, the maximum liquid yield of GVL-lignin of around $61 \%$ was obtained by using $0.075 \mathrm{M}$ sulfuric acid solution mixed with the $\mathrm{GVL} / \mathrm{H}_{2} \mathrm{O}$ binary solvent for lignin extraction. Finally, gaseous products obtained from GVL-lignin pyrolysis did not seem to be influenced by sulfuric acid concentration.

Figure 5B presents the fast pyrolysis liquid product distribution of extracted GVL-lignin with various sulfuric acid concentrations, with phenols as the dominant group. With an increasing sulfuric acid concentration used during extraction, the amount of phenols continuously increased, but at sulfuric acid concentrations provided by the addition of solutions with concentrations higher than $0.175 \mathrm{M}$, the phenols contents remained constant. On the contrary, the alkoxy phenols compounds in the liquid fraction decreased with increasing sulfuric acid concentration. The structures of GVL-lignin extracted with various sulfuric acid concentrations characterized by 2D HSQC NMR can explain these different liquid product distributions. Figure 6 illustrates the 2D HSQC NMR spectra of GVL-lignin extracted with various sulfuric acid concentrations. The major cross-signal in the side-chain $\left(\delta_{\mathrm{H}} / \delta_{\mathrm{C}} 2.5-5.8 / 50-90\right.$ ppm) region of the HSQC spectra of the GVL-lignins corresponded to the methoxy groups. This crosssignal decreased in intensity with increasing sulfuric acid concentration. The high sulfuric acid concentration induces dissociation of $\mathrm{O}-\mathrm{CH}_{3}$ bond located in the substructures of GVL-lignin ${ }^{70}$, decreasing the phenol alkoxy compounds in the liquid fraction at high sulfuric acid concentration. 
2D HSQC NMR also revealed other structural changes in GVL-lignin as a result of the influence of sulfuric acid. The $\mathrm{C}_{\gamma}-\mathrm{H}_{\gamma}$ in $\beta$-O-4' substructures (A) and $\mathrm{C}_{\gamma}-\mathrm{H}_{\gamma}$ in $\beta-5$ ' (phenylcoumaran) substructures $(\mathrm{C})$ decreased with increasing sulfuric acid concentration, because sulfuric acid can break down the hydroxy group $(-\mathrm{OH})$ in these substructures. In addition, considering the aromatic/unsaturated $\left(\delta_{\mathrm{H}} / \delta_{\mathrm{C}} 6.0-8.0 / 100-160 \mathrm{ppm}\right)$ region of the HSQC spectra, the cross-signals of $\mathrm{G}_{2}, \mathrm{G}_{5}$ and $\mathrm{G}_{6}$ decreased with increasing sulfuric acid concentration, because sulfuric acid decomposes these substructures. Furthermore, the loss of methoxy groups due to high sulfuric acid concentrations strongly influenced the $\mathrm{C}_{2}-\mathrm{H}_{2}$ correlation in guaiacyl units since methoxy groups in $\mathrm{G}$ substructure were the closest to the $\mathrm{C}_{2}-\mathrm{H}_{2}$ position, resulting in the disappearance of the $\mathrm{G}_{2}$ cross-signal. In contrast, $\mathrm{G}_{5}$ and $\mathrm{G}_{6}$ cross-signals still weakly emerged. The dissociation of methoxy groups lightly affected the $\mathrm{C}_{5}-\mathrm{H}_{5}$ and $\mathrm{C}_{6}-\mathrm{H}_{6}$ correlations compared to $\mathrm{C}_{2}-\mathrm{H}_{2}$ correlation in guaiacyl units. Moreover, using high sulfuric acid concentration in the lignin extraction process can lead to irreversible condensation of lignin. Rapid lignin condensation systematically occurs during most lignin extraction processes but is greatly accelerated by increasing acid concentrations. Under these conditions, a benzylic cation on $G$ substructures of lignin is easily generated, which reacts with another part of lignin, forming condensed structures via new stable carbon-carbon (C-C) bonds and decreasing $\mathrm{G}$ units. ${ }^{71}$
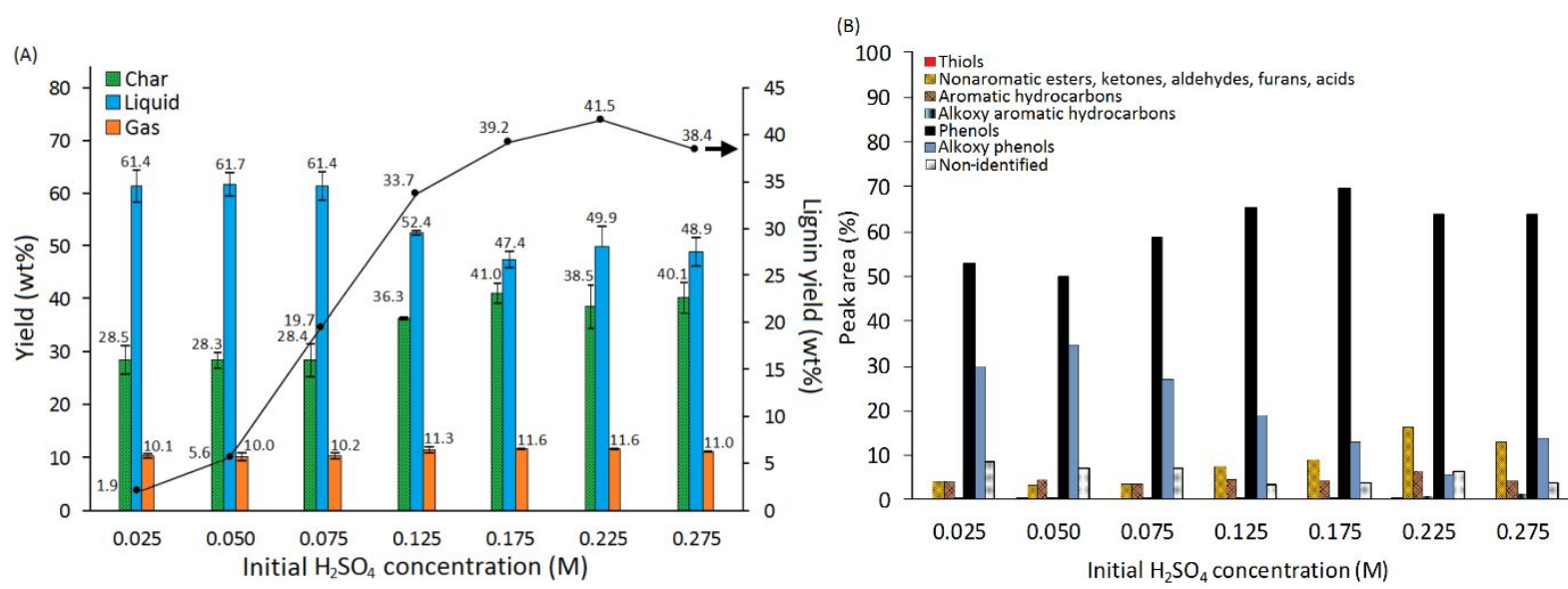

Figure 5 Effect of extracted lignin with various initial sulfuric acid concentrations [initial $\mathrm{GVL} / \mathrm{H}_{2} \mathrm{O}$ of $4 / 1(\mathrm{w} / \mathrm{w})$, at $160{ }^{\circ} \mathrm{C}$ for $24 \mathrm{~h}$ ] on pyrolysis and extracted lignin yields. (A) Lignin extraction yield (curve) and pyrolysis yields of char, liquid and gas (columns) and (B) Liquid product distribution. 

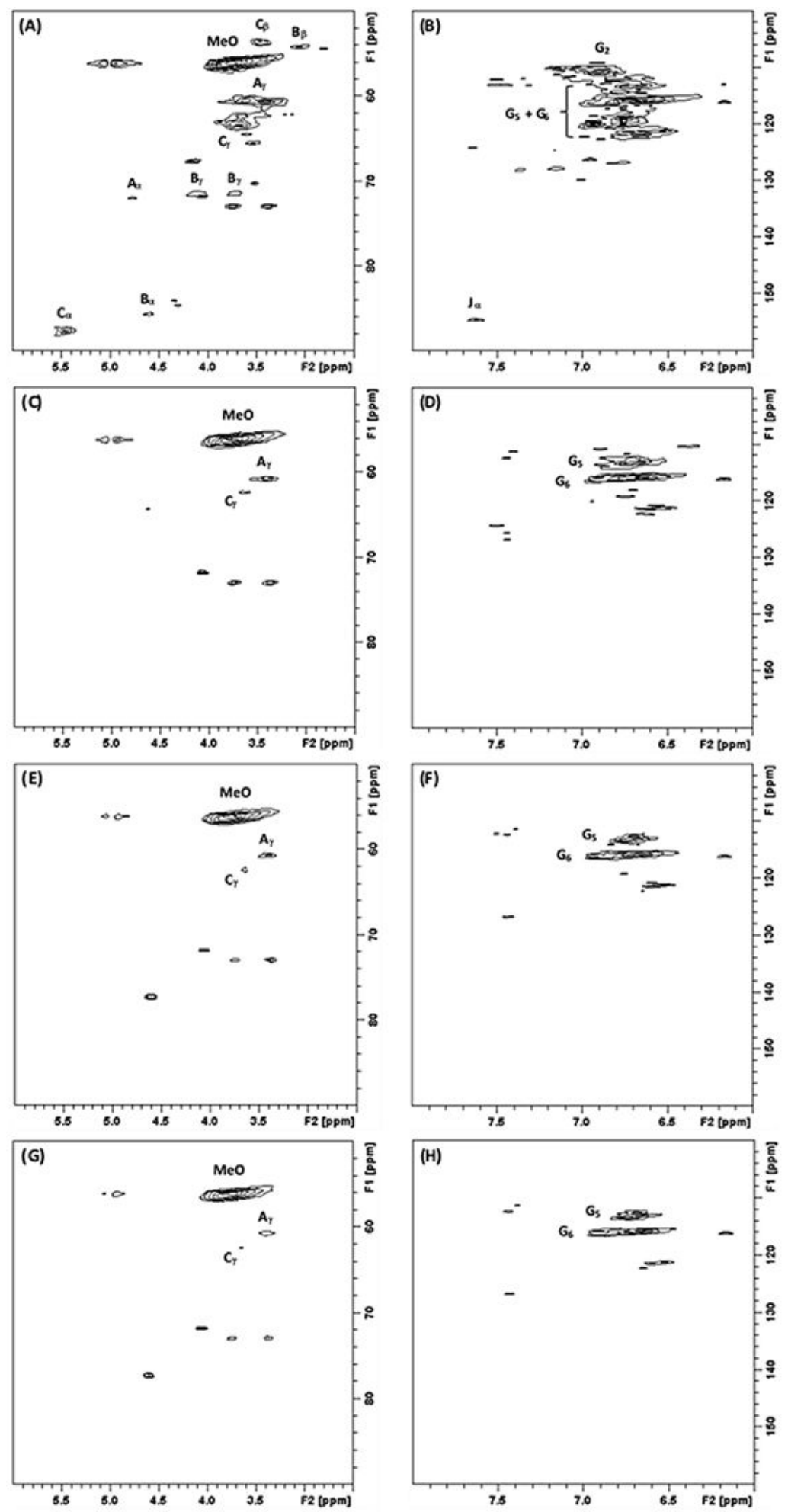

Figure 6 Side-chain $\left(\delta_{\mathrm{H}} / \delta_{\mathrm{C}} 2.5-5.8 / 50-90\right)$ and aromatic/unsaturated $\left(\delta_{\mathrm{H}} / \delta_{\mathrm{C}} 6.0-8.0 / 100-160\right)$ regions in the 2D HSQC NMR spectra of extracted lignin with $\mathrm{GVL} / \mathrm{H}_{2} \mathrm{O}$ [initial $\mathrm{GVL} / \mathrm{H}_{2} \mathrm{O}$ of $4 / 1$ (w/w)] and various sulfuric acid concentrations at $160^{\circ} \mathrm{C}$ for $24 \mathrm{~h}$. (A, B) initial $0.075 \mathrm{M}$ sulfuric acid; (C, D) initial $0.125 \mathrm{M}$ sulfuric acid; (E, F) initial $0.175 \mathrm{M}$ sulfuric acid and (G, H) initial $0.225 \mathrm{M}$ sulfuric acid. 
FTIR analyses (spectra in Figure S2 and interpretation in Table S5) were carried out to identify the functional groups existing in the structures of GVL-lignin extracted with various sulfuric acid concentrations. The characteristic bands presented in all spectra correspond to the ones reported in previous works. ${ }^{70,72-76}$ The characteristic bands at 2839 and $1210 \mathrm{~cm}^{-1}$, attributed to the $\mathrm{C}-\mathrm{H}$ stretching in $-\mathrm{OCH}_{3}$ and the $\mathrm{C}-\mathrm{O}$ stretching, respectively, can be used to analyze the structural changes of the GVL-lignins. The bands at $1595 \mathrm{~cm}^{-1}$, assigned to aromatic skeleton vibrations and independent of sulfuric acid concentration, were used to normalize those two peaks. The ratio of absorption value at $2849 \mathrm{~cm}^{-1}$ to $1595 \mathrm{~cm}^{-1}$ and the ratio of absorption value at $1210 \mathrm{~cm}^{-1}$ to $1595 \mathrm{~cm}^{-1}$ were identified as representative of $-\mathrm{OCH}_{3}$ and $\mathrm{C}-\mathrm{O}$, respectively. ${ }^{70}$ Table 2 shows the relative absorbance values at different sulfuric acid concentrations. For higher sulfuric acid concentrations, there is a decrease in the values related to $-\mathrm{OCH}_{3}$ groups while the corresponding values for $\mathrm{C}-\mathrm{O}$ increase. These results correspond to the 2D HSQC NMR involving the loss of methoxy groups while using high sulfuric acid concentration during GVL-lignin extraction and previous reports of Nikafshar and co-workers that found that the intensity of the signal at $1210 \mathrm{~cm}^{-1}$ increases after demethylation reactions. ${ }^{76}$ Moreover, the functional groups of GVL-lignin were confirmed by ${ }^{1} \mathrm{H}$ NMR (Figure S1). The ${ }^{1} \mathrm{H}$ NMR results showed that GVL-lignin consists of six major functional groups, in accordance with other lignins ${ }^{77}$ : formyl (10.08-9.47 ppm), phenolic (9.28-8.02 ppm), aromatic and vinyl (8.06-6.11 ppm), aliphatic $\mathrm{CH}-$ $\mathrm{O}, \mathrm{C}-\mathrm{CH}_{2}-\mathrm{O}$ (5.80-4.28 ppm), methoxy (4.28-3.05 ppm) and aliphatic C-CH $3, \mathrm{C}^{-} \mathrm{CH}_{2}-\mathrm{C}$ (2.16-0.00 ppm).

Structural changes occur in lignin due to mild acidic conditions during extraction. ${ }^{78}$ This is noted from the signals related to the side-chains of lignin obtained with different sulfuric acid concentrations (Figure 6) in accordance with loss of $\beta-\mathrm{O}-4$ structures, producing more condensed structures. TGA analysis and its first derivative representation (DTG) confirm these changes in lignins structures. TGA and DTG results (Figure S3 and Table S6) show one main event centered around 400 ${ }^{\circ} \mathrm{C}$ associated with lignin decomposition. The temperature of maximum devolatilization rate increases for higher concentration of sulfuric acid used in the extraction process. This trend suggests that more stable lignin structures form at higher sulfuric acid concentrations due to greater extent of condensation and the presence of strong $\mathrm{C}-\mathrm{C}$ bonds. ${ }^{57,79,80}$ In addition, there is an important decrease in the maximum 
devolatilization rate of GVL-lignins extracted with mixtures containing solutions of initial concentration of $0.125-0.275 \mathrm{M}$ sulfuric acid with respect to $0.075 \mathrm{M}$ sulfuric acid, which is consistent with previous results reported by Gardner and co-workers, who demonstrated a significant decrease in the rate of weight loss for more condensed lignins. ${ }^{79}$

The results evidence that the extraction conditions affect the lignin and then the products distribution in fast pyrolysis. However, GVL-lignin remains more similar to native lignin compared to other extraction methods, especially those involving aqueous conditions with high acid concentration, as demonstrated Luterbacher and co-workers. ${ }^{28}$ Therefore, a fine-tuning of the conditions may enable improved control of the selectivity in fast pyrolysis.

Table 2 Relative absorbance values of functional groups presented in GVL-lignin obtained by FTIR.

\begin{tabular}{c|c|c|c|c|c|c}
\hline \multirow{2}{*}{$\begin{array}{c}\text { Wavenumber } \\
\left(\mathrm{cm}^{-1}\right)\end{array}$} & \multicolumn{5}{|c|}{ Relative absorbance values at various initial sulfuric acid } & \multirow{2}{*}{ Assignment } \\
\cline { 2 - 6 } & $0.075 \mathrm{M}$ & $0.125 \mathrm{M}$ & $0.175 \mathrm{M}$ & $0.225 \mathrm{M}$ & $0.275 \mathrm{M}$ & \\
\hline 2839 & 0.438 & 0.350 & 0.335 & 0.333 & 0.329 & C-H stretching in $-\mathrm{OCH}_{3}$ \\
\hline 1595 & 1.000 & 1.000 & 1.000 & 1.000 & 1.000 & Aromatic skeleton vibrations \\
\hline 1210 & 1.242 & 1.285 & 1.347 & 1.354 & 1.372 & C-O stretching \\
\hline
\end{tabular}

\section{Conclusions}

The precise composition of the extraction medium influences the extraction yield of GVLlignin and subtly affects its resulting structure. The GVL-to-water ratio affects the lignin yield, while minimally affecting the lignin structure. In contrast, the sulfuric acid concentration during the extraction affects both the extraction yield and the lignin structure, resulting in higher yields and more modified lignins for higher acid concentrations. These structural changes influence the products distribution after fast pyrolysis. Further fine-tuning of the extraction conditions could facilitate selectivity control in fast pyrolysis of lignin. 


\author{
Author Information \\ *Corresponding author: Tel.: +41 44632 5542. E-mail address: jeroen.vanbokhoven@chem.ethz.ch \\ (Jeroen A. van Bokhoven) \\ \#These authors contributed equally to this work.
}

ORCID

Allen Puente-Urbina: https://orcid.org/0000-0001-5328-2142

Zhiqiang Ma: https://orcid.org/0000-0003-3713-3926

Sujitra Wongkasemjit: https://orcid.org/0000-0003-4501-8848

Jeremy S. Luterbacher: http://orcid.org/0000-0002-0967-0583

Jeroen A. van Bokhoven: http://orcid.org/0000-0002-4166-2284

\title{
Acknowledgements
}

The authors would like to thank to the Development and Promotion of Science and Technology Talents Project, the Ministry of Science and Technology, Thailand, the Thailand Research Fund (Senior Research Scholar), the Ministry of Science, Technology and Telecommunications of Costa Rica and the Costa Rica Institute of Technology for their support.

\section{Supporting Information}

Additional information about the solutions used for lignin extraction, lignin extraction yields and characterization (NMR, FTIR TGA and DTG).

\section{References}

(1) Wang, S.; Dai, G.; Yang, H.; Luo, Z. Lignocellulosic biomass pyrolysis mechanism: A state-of-theart review. Prog. Energ. Combust. 2017, 62, 33 - 86, DOI 10.1016/j.pecs.2017.05.004.

(2) Qi, Z.; Jie, C.; Tiejun, W.; Ying, X. Review of biomass pyrolysis oil properties and upgrading research. Energ. Convers. Manage. 2007, 48 (1), 87 - 92, DOI 10.1016/j.enconman.2006.05.010. 
(3) Gallezot, P. Conversion of biomass to selected chemical products. Chem. Soc. Rev. 2012, 41, 1538 - 1558, DOI 10.1039/C1CS15147A.

(4) Shen, D.; Jin, W.; Hu, J.; Xiao, R.; Luo, K. An overview on fast pyrolysis of the main constituents in lignocellulosic biomass to valued-added chemicals: Structures, pathways and interactions. Renew. Sust. Energ. Rev. 2015, 51, 761 - 774, DOI 10.1016/j.rser.2015.06.054.

(5) Steubing B., Zah R., Waeger P., Ludwig, C. Bioenergy in Switzerland: Assessing the domestic sustainable biomass potential. Renew. Sust. Energ. Rev., 2010, 14 (8), 2256 - 2265, DOI 10.1016/j.rser.2010.03.036.

(6) Swiss National Forest Inventory; Swiss Federal Institute for Forest, Snow and Landscape Research and Federal Office for the Environment: Switzerland, 2018; http://www.lfi.ch/.

(7) Stefanidis, S. D.; Kalogiannis, K. G.; Iliopoulou, E. F.; Michailof, C. M.; Pilavachi, P. A.; Lappas A. A. A study of lignocellulosic biomass pyrolysis via the pyrolysis of cellulose, hemicellulose and lignin. J. Anal. Appl. Pyrol. 2014, 105, 143 - 150, DOI 10.1016/j.jaap.2013.10.013.

(8) Kabir, G.; Hameed, B. H. Recent progress on catalytic pyrolysis of lignocellulosic biomass to high grade bio-oil and bio-chemicals. Renew. Sust. Energ. Rev. 2017, 70, 945 - 967, DOI 10.1016/j.rser.2016.12.001.

(9) Kumar, P.; Barrett, D. M.; Delwiche, M. J.; Stroeve, P. Methods for pretreatment of lignocellulosic biomass for efficient hydrolysis and biofuel production. Ind. Eng. Chem. Res. 2009, 48 (8), 3713 -3729, DOI 10.1021/ie801542g.

(10) Crestini, C.; Melone, F.; Sette, M.; Saladino, R. Milled wood lignin: A linear oligomer. Biomacromolecules 2011, 12 (11), 3928 - 3935, DOI 10.1021/bm200948r.

(11) Lapierre, C.; Pollet, B.; Rolando, C. New insights into the molecular architecture of hardwood lignins by chemical degradative methods. Res. Chem. Intermediat. 1995, 21, 397 - 412, DOI 10.1007/BF03052266.

(12) Neutelings, G. Lignin variability in plant cell walls: Contribution of new models. Plant Sci. 2011, 181 (4), 379 - 386, DOI 10.1016/j.plantsci.2011.06.012.

(13) Dhyani, V.; Bhaskar, T. A comprehensive review on the pyrolysis of lignocellulosic biomass. Renew. Energ. 2018, 129, 695 - 716, DOI 10.1016/j.renene.2017.04.035. 
(14) Behera, S.; Arora, R.; Nandhagopal, N.; Kumar, S. Importance of chemical pretreatment for bioconversion of lignocellulosic biomass. Renew. Sust. Energ. Rev. 2014, 36, 91 - 106, DOI 10.1016/j.rser.2014.04.047.

(15) Taherzadeh, M. J.; Karimi, K. Pretreatment of lignocellulosic wastes to improve ethanol and biogas production: A review. Int. J. Mol. Sci. 2008, 9 (9), 1621 - 1651, DOI 10.3390/ijms9091621.

(16) Shuai, L.; Talebi Amiri, M.; Luterbacher, J. S. The influence of interunit carbon-carbon linkages during lignin upgrading. Curr. Opin. Green Sustain. Chem. 2016, 2, 59 - 63, DOI 10.1016/j.cogsc.2016.10.001.

(17) Schutyser, W.; Renders, T.; Van den Bosch, S.; Koelewijn, S.-F.; Beckham, G. T.; Sels, B. F. Chemicals from lignin: An interplay of lignocellulose fractionation, depolymerisation, and upgrading. Chem. Soc. Rev. 2018, 47, 852 - 908, DOI 10.1039/C7CS00566K.

(18) Sun, Z.; Fridrich, B.; de Santi, A.; Elangovan, S.; Barta, K. Bright side of lignin depolymerization: Toward new platform chemicals. Chem. Rev. 2018, 118 (2), 614 - 678, DOI 10.1021/acs.chemrev.7b00588.

(19) Rinaldi, R.; Jastrzebski, R.; Clough, M. T.; Ralph, J.; Kennema, M.; Bruijnincx, P. C. A.; Weckhuysen, B. M. Paving the way for lignin valorisation: Recent advances in bioengineering, biorefining and catalysis. Angew. Chemie Int. Ed. 2016, 55 (29), 8164 - 8215, DOI 10.1002/anie.201510351.

(20) Sun, F.; Chen, H. Organosolv pretreatment by crude glycerol from oleochemicals industry for enzymatic hydrolysis of wheat straw. Bioresource Technol. 2008, 99 (13), 5474 - 5479, DOI 10.1016/j.biortech.2007.11.001.

(21) Agbor, V. B.; Cicek, N.; Sparling, R.; Berlin, A.; Levin D. B. Biomass pretreatment: Fundamentals toward application. Biotechnol. Adv. 2011, 29 (6), $675 \quad-\quad 685$, DOI 10.1016/j.biotechadv.2011.05.005.

(22) Zhao, X.; Li, S.; Wu, R.; Liu, D. Organosolv fractionating pre-treatment of lignocellulosic biomass for efficient enzymatic saccharification: Chemistry, kinetics, and substrate structures. Biofuel. Bioprod. Bior. 2017, 11 (3), 567 - 590, DOI 10.1002/bbb.1768. 
(23) Wen, J.-L.; Sun, S.-L.; Yuan, T.-Q.; Xu, F.; Sun, R.-C. structural elucidation of lignin polymers of Eucalyptus Chips during organosolv pretreatment and extended delignification. J. Agric. Food Chem. 2013, 61 (46), 11067 - 11075, DOI 10.1021/jf403717q.

(24) Soh, L.; Eckelman, M. J. Green solvents in biomass processing. ACS Sustain. Chem. Eng. 2016, 4 (11), 5821 - 5837, DOI 10.1021/acssuschemeng.6b01635.

(25) Lê, H. Q.; Ma, Y.; Borrega, M.; Sixta, H. Wood biorefinery based on $\gamma$-valerolactone/water fractionation. Green Chem. 2016, 18, 5466 - 5476, DOI 10.1039/C6GC01692H.

(26) Fang, W.; Sixta, H. Advanced biorefinery based on the fractionation of biomass in $\gamma$-valerolactone and water. ChemSusChem 2015, 8 (1), 73 - 76, DOI 10.1002/cssc.201402821.

(27) Li, S.-X.; Li, M.-F.; Yu, P.; Fan, Y.-M.; Shou, J.-N.; Sun, R.-C. Valorization of bamboo by $\gamma-$ valerolactone/acid/water to produce digestible cellulose, degraded sugars and lignin. Bioresource Technol. 2017, 230, 90 - 96, DOI 10.1016/j.biortech.2017.01.041.

(28) Luterbacher, J. S.; Azarpira, A.; Motagamwala, A. H.; Lu, F.; Ralph, J.; Dumesic, J. A. Lignin monomer production integrated into the $\gamma$-valerolactone sugar platform. Energ. Environ. Sci. 2015, 8, 2657 - 2663, DOI 10.1039/C5EE01322D.

(29) Angelini, S.; Ingles, D.; Gelosia, M.; Cerruti, P.; Pompili, E.; Scarinzi, G.; Cavalaglio, G.; Cotana, F.; Malinconico, M. One-pot lignin extraction and modification in $\gamma$-valerolactone from steam explosion pre-treated lignocellulosic biomass. J. Clean. Prod. 2017, 151, 152 - 162, DOI 10.1016/j.jclepro.2017.03.062.

(30) Tang, X.; Zeng, X.; Li, Z.; Hu, L.; Sun, Y.; Liu, S.; Lei, T.; Lin, L. Production of $\gamma$-valerolactone from lignocellulosic biomass for sustainable fuels and chemicals supply. Renew. Sust. Energ. Rev. 2014, 40, 608 - 620, DOI 10.1016/j.rser.2014.07.209.

(31) Alonso, D. M.; Wettstein, S. G.; Mellmer, M. A.; Gurbuz, E. I.; Dumesic, J. A. Integrated conversion of hemicellulose and cellulose from lignocellulosic biomass. Energ. Environ. Sci. 2013, 6, 76 - 80, DOI 10.1039/C2EE23617F. 
(32) Horvath, I. T.; Mehdi, H.; Fabos, V.; Boda, L.; Mika, L. T. $\gamma$-Valerolactone-a sustainable liquid for energy and carbon-based chemicals. Green Chem. 2008, 10, 238 - 242, DOI 10.1039/B712863K.

(33) Fegyverneki, D.; Orha, L.; Láng, G.; Horváth, I. T. Gamma-valerolactone-based solvents. Tetrahedron 2010, 66 (5), 1078 - 1081, DOI 10.1016/j.tet.2009.11.013.

(34) Emelyanenko, V. N.; Kozlova, S. A.; Verevkin, S. P.; Roganov, G. N. Vapour pressures and enthalpies of vapourization of a series of the $\gamma$-lactones. J. Chem. Thermodyn. 2008, 40 (6), $911-$ 916, DOI 10.1016/j.jct.2008.02.002.

(35) Sharma, A.; Pareek, V.; Zhang, D. Biomass pyrolysis-A review of modelling, process parameters and catalytic studies. Renew. Sust. Energ. Rev. 2015, 50, 1081 - 1096, DOI 10.1016/j.rser.2015.04.193.

(36) Laurichesse, S.; Avérous, L. Chemical modification of lignins: Towards biobased polymers. Prog. Polym. Sci. 2014, 39 (7), 1266 - 1290, DOI 10.1016/j.progpolymsci.2013.11.004.

(37) Bu, Q.; Lei, H.; Ren, S. J.; Wang, L.; Holladay, J.; Zhang, Q.; Tang, J.; Ruan, R. Phenol and phenolics from lignocellulosic biomass by catalytic microwave pyrolysis. Bioresource Technol. 2011, 102 (13), 7004 - 7007, DOI 10.1016/j.biortech.2011.04.025.

(38) Yaman, S. Pyrolysis of biomass to produce fuels and chemical feedstocks. Energ. Convers. Manage. 2004, 45 (5), 651 - 671, DOI 10.1016/S0196-8904(03)00177-8.

(39) Li, C.; Zhao, X.; Wang, A.; Huber, G. W.; Zhang, T. Catalytic transformation of lignin for the production of chemicals and fuels. Chem. Rev. 2015, 115 (21), 11559 - 11624, DOI 10.1021/acs.chemrev.5b00155.

(40) Bridgwater, A. V. Review of fast pyrolysis of biomass and product upgrading. Biomass Bioenerg. 2012, 38, 68 - 94, DOI 10.1016/j.biombioe.2011.01.048.

(41) Hemberger, P.; Custodis, V. B. F.; Bodi, A.; Gerber, T.; van Bokhoven, J. A. Understanding the mechanism of catalytic fast pyrolysis by unveiling reactive intermediates in heterogeneous catalysis. Nat. Commun. 2017, 8, DOI 10.1038/ncomms 15946. 
(42) Ma, Z.; Ghosh, A.; Asthana, N.; van Bokhoven, J. A. Optimization of the reaction conditions for catalytic fast pyrolysis of pretreated lignin over zeolite for the production of phenol. ChemCatChem 2017, 9 (6), 954 - 961, DOI 10.1002/cctc.201601674.

(43) Custodis, V. B. F.; Karakoulia, S. A.; Triantafyllidis, K. S.; van Bokhoven, J. A. Catalytic Fast Pyrolysis of Lignin over High-Surface-Area Mesoporous Aluminosilicates: Effect of Porosity and Acidity. ChemSusChem 2016, 9 (10), 1134 - 1145, DOI 10.1002/cssc.201600105.

(44) Custodis, V. B. F.; Bährle, C.; Vogel, F.; van Bokhoven, J. A. Phenols and aromatics from fast pyrolysis of variously prepared lignins from hard- and softwoods. J. Anal. Appl. Pyrol. 2015, 115, 214 - 223, DOI 10.1016/j.jaap.2015.07.018.

(45) Ma, Z.; Troussard, E.; van Bokhoven, J. A. Controlling the selectivity to chemicals from lignin via catalytic fast pyrolysis. Appl. Catal. A-Gen. 2012, 423-424, 130 - 136, DOI 10.1016/j.apcata.2012.02.027.

(46) Bährle, C.; Custodis, V.; Jeschke, G.; van Bokhoven, J. A., Vogel, F. The influence of zeolites on radical formation during lignin pyrolysis. ChemSusChem 2016, 9 (17), 2397 - 2403, DOI $10.1002 /$ cssc. 201600582 .

(47) Ma, Z.; Custodis, V.; van Bokhoven, J. A. Selective deoxygenation of lignin during catalytic fast pyrolysis. Catal. Sci. Technol. 2014, 4, 766 - 772, DOI 10.1039/C3CY00704A.

(48) Ma, Z.; van Bokhoven, J. A. Deactivation and regeneration of H-USY zeolite during lignin catalytic fast pyrolysis. Chem CatChem 2012, 4 (12), 2036 - 2044, DOI 10.1002/cctc.201200401.

(49) Kim, Y. M.; Jae, J.; Myung, S.; Sung, B. H.; Dong, J. I.; Park, Y. K. Investigation into the lignin decomposition mechanism by analysis of the pyrolysis product of Pinus radiata. Bioresource Technol. 2016, 219, 371 - 377, DOI 10.1016/j.biortech.2016.08.001.

(50) Onay, O. Influence of pyrolysis temperature and heating rate on the production of bio-oil and char from safflower seed by pyrolysis, using a well-swept fixed-bed reactor. Fuel Process. Technol. 2007, 88 (5), 523 - 531, DOI 10.1016/j.fuproc.2007.01.001.

(51) Horne, P. A.; Williams, P. T. Influence of temperature on the products from the flash pyrolysis of biomass. Fuel 1996, 75 (9), 1051 - 1059, DOI 10.1016/0016-2361(96)00081-6. 
(52) Heo, H. S.; Park, H. J.; Dong, J. I.; Park, S. H.; Kim, S.; Suh, D. J.; Suh, Y. W.; Kim, S. S.; Park, Y. K. Fast pyrolysis of rice husk under different reaction conditions. J. Ind. Eng. Chem. 2010, 16 (1), 27 - 31, DOI 10.1016/j.jiec.2010.01.026.

(53) Naqvi, S. R.; Uemura, Y.; Yusup S. B. Catalytic pyrolysis of paddy husk in a drop type pyrolyzer for bio-oil production: The role of temperature and catalyst. J. Anal. Appl. Pyrol. 2014, 106, 57 62, DOI 10.1016/j.jaap.2013.12.009.

(54) Imam, T.; Capareda, S. Characterization of bio-oil, syn-gas and bio-char from switchgrass pyrolysis at various temperatures. J. Anal. Appl. Pyrol. 2012, 93, 170 - 177, DOI 10.1016/j.jaap.2011.11.010.

(55) Lê, H. Q.; Zaitseva, A.; Pokki, J.-P.; Ståhl, M.; Alopaeus, V.; Sixta, H. Solubility of organosolv lignin in $\gamma$-valerolactone/water binary mixtures. ChemSusChem 2016, 9 (20), 2939 - 2947, DOI $10.1002 /$ cssc. 201600655 .

(56) Brasch, D. J.; Free, K. W. Prehydrolysis-Kraft pulping of Pinus radiata grown in New Zealand. Tappi 1965, 48, $245-248$.

(57) Pepper, J. M.; Siddiqueullah, M. The effect of initial acid concentration on the lignin isolated by the acidolysis of aspen wood. Cana. J. Chem. 1961, 39 (7), 1454 - 1461, DOI 10.1139/v61-185.

(58) Wong, C. Y. Y.; Choi, A. W.-T.; Lui, M. Y.; Fridrich, B.; Horváth, A. K.; Mika, L. T.; Horváth, I. T. Stability of gamma-valerolactone under neutral, acidic, and basic conditions. Struct. Chem. 2017, 28 (2), 423 - 429, DOI 10.1007/s11224-016-0887-6.

(59) Xue, Z.; Zhao, X.; Sun, R. C.; Mu, T. Biomass-derived $\gamma$-valerolactone-based solvent systems for highly efficient dissolution of various lignins: dissolution behavior and mechanism study. ACS Sustain. Chem. Eng. 2016, 4 (7), 3864 - 3870, DOI 10.1021/acssuschemeng.6b00639.

(60) Luterbacher, J. S.; Rand, J. M.; Alonso, D. M.; Han, J.; Youngquist, J. T.; Maravelias, C. T.; Pfleger, B. F.; Dumesic, J. A. Nonenzymatic sugar production from biomass using biomassderived $\gamma$-valerolactone. Science 2014, 343 (6168), 277 - 280, DOI 10.1126/science. 1246748.

(61) Jiang, G.; Nowakowski, D. J.; Bridgwater, A. V. Effect of the temperature on the composition of lignin pyrolysis products. Energ. Fuel., 2010, 24 (8), 4470 - 4475, DOI 10.1021/ef100363c. 
(62) Trinh, T. N.; Jensen, P. A.; Sárossy, Z.; Dam-Johansen, K.; Knudsen, N. O.; Sørensen, H. R.; Egsgaard, H. Fast pyrolysis of lignin using a pyrolysis centrifuge reactor. Energ. Fuel., 2013, 27 (7), $3802-3810$, DOI 10.1021/ef400527k.

(63) Zhao, Y.; Deng, L.; Liao, B.; Fu, Y.; Guo, Q. X. Aromatics production via catalytic pyrolysis of pyrolytic lignins from bio-oil. Energ. Fuel., 2010, 24 (10), 5735 - 5740, DOI 10.1021/ef100896q.

(64) Li, X.; Su, L.; Wang, Y.; Yu, Y.; Wang, C.; Li, X.; Wang, Z. Catalytic fast pyrolysis of Kraft lignin with HZSM-5 zeolite for producing aromatic hydrocarbons. Front. Env. Sci. Eng. 2012, 6 (3), 295 -303, DOI 10.1007/s11783-012-0410-2.

(65) Patwardhan, P. R.; Brown, R. C.; Shanks, B. H. Understanding the fast pyrolysis of lignin. ChemSusChem 2011, 4 (1), 1629 - 1636, DOI 10.1002/cssc.201100133.

(66) Fan, L.; Zhang, Y.; Liu, S.; Zhou, N.; Chen, P.; Cheng, Y.; Addy, M.; Lu, Q.; Omar, M. M.; Liu, Y.; Wang, Y.; Dai, L.; Anderson, E.; Peng, P.; Lei, H.; Ruan, R. Bio-oil from fast pyrolysis of lignin: Effects of process and upgrading parameters. Bioresource Technol. 2017, 241, 1118 - 1126, DOI 10.1016/j.biortech.2017.05.129.

(67) Lourenço, A.; Rencoret, J.; Chemetova, C.; Gominho, J.; Gutiérrez, A.; del Río, J. C.; Pereira, H. Lignin composition and structure differs between xylem, phloem and phellemin Quercussuber L. Front. Plant Sci. 2016, 7, DOI 10.3389/fpls.2016.01612.

(68) Rencoret, J.; Marques, G.; Gutiérrez, A.; Nieto, L.; Santos, J. I.; Jimenez-Barbero, J.; Martínez, A. T., del Río J. C. HSQC-NMR analysis of lignin in woody (Eucalyptus globulus and Picea abies) and non-woody (Agave sisalana) ball-milled plant materials at the gel state. Holzforschung $\mathbf{2 0 0 9}$, 63 (6), $691-698$, DOI 10.1515/HF.2009.070.

(69) Martínez, A. T.; Rencoret, J.; Marques, G.; Gutiérrez, A.; Ibarra, D.; Jiménez-Barbero, J.; del Río J. C. Monolignol acylation and lignin structure in some nonwoody plants: A 2D NMR study. Phytochemistry 2008, 69 (16), 2831 - 2843, DOI 10.1016/j.phytochem.2008.09.005.

(70) Li, J.; Wang, W.; Zhang, S.; Gao, Q.; Zhang, W.; Li, J. Preparation and characterization of lignin demethylated at atmospheric pressure and its application in fast curing biobased phenolic resins. RSC Adv. 2016, 6, 67435 - 67443, DOI 10.1039/C6RA11966B. 
(71) Shuai, L.; Amiri, M. T.; Questell-Santiago, Y. M.; Héroguel, F.; Li, Y.; Kim, H.; Meilan, R.; Chapple, C.; Ralph, J.; Luterbacher, J. S. Formaldehyde stabilization facilitates lignin monomer production during biomass depolymerization. Science 2016, 354 (6310), 329 - 333, DOI 10.1126/science.aaf7810.

(72) Hage, R. E.; Brosse, N.; Chrusciel, L.; Sanchez, C.; Sannigrahi, P.; Ragauskas, A. Characterization of milled wood lignin and ethanol organosolv lignin from miscanthus. Polym. Degrad. Stabil. 2009, 94 (10), 1632 - 1638, DOI 10.1016/j.polymdegradstab.2009.07.007.

(73) Azadfar, M.; Gao, A. H.; Bule, M. V.; Chen, S. Structural characterization of lignin: A potential source of antioxidants guaiacol and 4-vinylguaiacol. Int. J. Biol. Macromol. 2015, 75, 58 - 66, DOI 10.1016/j.ijbiomac.2014.12.049.

(74) Jahan, M. S.; Chowdhury, D. A. N.; Islam, M. K.; Moeiz, S. M. I. Characterization of lignin isolated from some nonwood available in Bangladesh. Bioresource Technol. 2007, 98 (2), 465 469, DOI 10.1016/j.biortech.2006.01.005.

(75) Wu, M.; Liu, J.-K.; Yan, Z.-Y.; Wang, B.; Zhang, X.-M.; Xu, F.; Sun, R.-C. Efficient recovery and structural characterization of lignin from cotton stalk based on a biorefinery process using a $\gamma$ valerolactone/water system. $R S C A d v$., 2016, 6, 6196 - 6204, DOI 10.1039/C5RA23095K.

(76) Nikafshar, S.; Zabihi, O.; Moradi, Y.; Ahmadi, M.; Amiri, S.; Naebe, M. Catalyzed synthesis and characterization of a novel lignin-based curing agent for the curing of high-performance epoxy resin. Polymers. 2017, 9 (7), 266, DOI 10.3390/polym9070266.

(77) Cheng, Y.; Zhao, P. X.; Alma, M. H.; Sun, D. F.; Li, R.; Jiang, J. X. Improvement of direct liquefaction of technical alkaline lignin pretreated by alkaline hydrogen peroxide. J. Anal. Appl. Pyrol. 2016, 122, 277 - 281, DOI 10.1016/j.jaap.2016.07.022.

(78) Santos, R. B.; Harte, P. W.; Jameel, H.; Chang, H. Wood based lignin reactions important to the biorefinery and pulp and paper industries. Bioresources 2013, 8, 1456 - 1477.

(79) Gardner, D. J.; Schultz, T. P.; McGinnis, G. D. The pyrolytic behavior of selected lignin preparations. J. Wood Chem. Technol. 1985, 5 (1), 85 - 110, DOI 10.1080/02773818508085182. 
(80) Kim J.-Y., Hwang H., Oh S., Kim Y.-S., Kim U.-J., Choi, J. W. Investigation of structural modification and thermal characteristics of lignin after heat treatment. Int. J. Biol. Macromol. 2014, 66, 57 - 65, DOI 10.1016/j.ijbiomac.2014.02.013. 


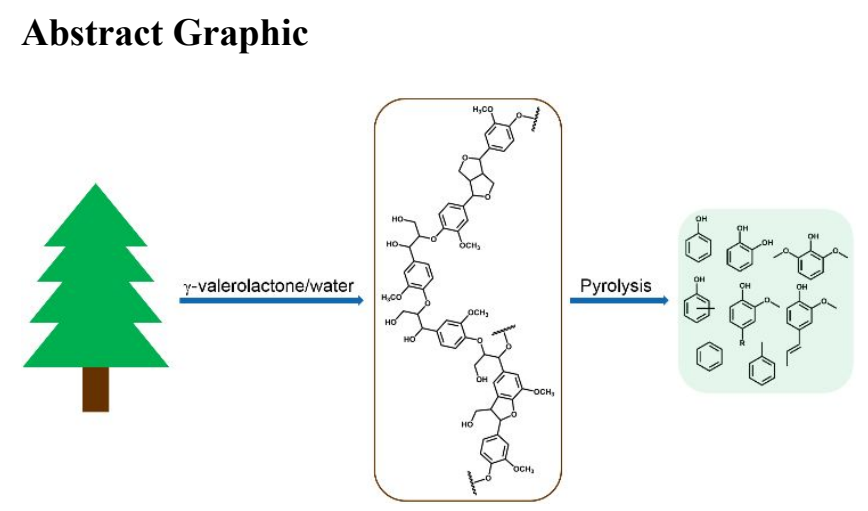

\section{Synopsis}

The extraction conditions of lignin using a solvent system containing $\gamma$-valerolactone and water affect the selectivity in fast pyrolysis. 